\title{
State of the Art of Superalloy Production for Aerospace and Other Application Using VIM/VAR or VIM/ESR
}

\author{
Alok CHOUDHURY \\ Metallurgical Department, LEYBOLD DURFERRIT GmbH, Rueckinger Straße 12, 6455 Erlensee, Germany.
}

(Received on December 9, 1991; accepted in final form on February 28, 1992)

\begin{abstract}
Vacuum induction melting is indispensable in the manufacture of $\mathrm{Ni}$ - and $\mathrm{Co}$-based superalloys and other sophisticated alloys because of their reactivity with atmospheric oxygen and nitrogen. The paper describes the technology of melting and refining in a vacuum induction furnace, the programmable furnace control and metallurgical results. The paper also describes subsequent remelting processes like VAR and ESR which make it possible to meet the very high quality requirements for aerospace applications.
\end{abstract}

KEY WORDS: VIM; VIDP; superalloys; vacuum arc remelting; electroslag remelting; ingot defects.

\section{Introduction}

Superalloys can be defined as iron-, nickel- or cobalt-based alloys having high strength and high resistance to oxidation properties at temperatures above $650^{\circ} \mathrm{C}$. The structure of superalloys is basically an austenitic FCC $\gamma$-phase with a number of secondary phases like carbides, $\mathrm{MC}, \mathrm{M}_{23} \mathrm{C}_{6}, \mathrm{M}_{6} \mathrm{C}$ and gammaprime $\left(\gamma^{\prime}\right)$. In order to achieve a micro-structure allowing high strength and resistance to oxidation among other properties at high working temperature the chemical composition of superalloys is rather complex and includes a variety of alloying elements of different concentrations. Table 1 shows the main alloying additions and their structural effect in different types of superalloys. ${ }^{1)}$

The superalloys also contain several other reactive elements like $\mathrm{Ti}, \mathrm{Al}, \mathrm{Nb}, \mathrm{Ta}, \mathrm{Zr}, \mathrm{B}$ and $\mathrm{Hf}$ in more or

Table 1. Common ranges of main alloying additions and their effects in superalloys.

\begin{tabular}{|c|c|c|c|}
\hline \multirow[b]{2}{*}{ Element } & \multicolumn{2}{|c|}{ Range in $w t \%$} & \multirow[b]{2}{*}{ Effects } \\
\hline & $\begin{array}{l}\mathrm{FeNi} \text { - and } \\
\mathrm{Ni} \text {-base }\end{array}$ & Co-base & \\
\hline $\mathrm{Cr}$ & $5-25$ & $19-30$ & $\begin{array}{l}\text { Oxidation and hot corrosion resis- } \\
\text { tance; carbides; solution hardening }\end{array}$ \\
\hline Mo, W & $0-12$ & $0-11$ & Carbides; solution hardening \\
\hline $\mathrm{Al}$ & $0-6$ & $0-4.5$ & $\begin{array}{l}\text { Precipitation hardening; oxidation } \\
\text { resistance }\end{array}$ \\
\hline $\mathrm{Ti}$ & $0-6$ & $0-4$ & Precipitation hardening; carbides af- \\
\hline Co & $0-20$ & - & fects amount of precipitate \\
\hline $\mathrm{Ni}$ & - & $0-22$ & $\begin{array}{l}\text { Stabilizes austenite; forms harden- } \\
\text { ing precipitates }\end{array}$ \\
\hline $\mathrm{Cb}$ & $0-5$ & $0-4$ & $\begin{array}{l}\text { Carbides; solution hardening; pre- } \\
\text { cipitation hardening (FeNi- and } \mathrm{Ni}- \\
\text { base) }\end{array}$ \\
\hline $\mathrm{Ta}$ & $0-12$ & $0-9$ & $\begin{array}{l}\text { Carbides; solution hardening; oxi- } \\
\text { dation resistance }\end{array}$ \\
\hline
\end{tabular}

less high concentrations. As these elements are of primary importance for the properties of a material their concentration must be kept within a narrow analytical range in order to assure that the properties are reproducible. Accordingly, during melting of these alloys every care must be taken to avoid any undesired reactions, such as with air, increasing loss of these elements, deterioration in oxide and nitride cleanliness. The melting of superalloys should therefore be carried out under vacuum or in an inertgas atmosphere.

\section{Metallurgy of Vacuum Induction Melting (VIM)}

VIM is the most versatile melting process for the production of speciality alloys. ${ }^{2-6)}$ This melting process allows the best control over the entire alloy chemistry including beneficial and harmful trace elements. Apart from this, the reproducibility of exact composition control from heat to heat is completely assured. Table 2 shows, for example, the excellent chemistry control of IN-718. ${ }^{7,8)}$ Special features of vacuum induction melting can be summarized as follows:

- flexibility due to small batch sizes

- faster change of melt programme

Table 2. Chemical composition control of $[\mathrm{N}-718$ based on 100 heats.

\begin{tabular}{lccccc}
\hline Element & $\begin{array}{c}\text { Specific } \\
\text { range } \\
\text { in } \%\end{array}$ & $\begin{array}{c}\text { Final } \\
\text { range } \\
\text { in \% }\end{array}$ & $\begin{array}{c}\text { Analytical Analytical acurracy } \\
\text { rrequency } \\
\text { in \%* }\end{array}$ & $\begin{array}{c}\text { in \%* } \\
1971 \text { data }\end{array}$ \\
\hline $\mathrm{C}$ & $0.02-0.08$ & $0.04-0.05$ & 95 & \pm 0.006 & \pm 0.003 \\
$\mathrm{Ti}$ & $0.80-1.15$ & $0.90-1.10$ & 97 & \pm 0.05 & \pm 0.03 \\
$\mathrm{Cb}$ & $4.75-5.50$ & $5.05-5.40$ & 99 & \pm 0.12 & \pm 0.08 \\
$\mathrm{Al}$ & $0.30-0.70$ & $0.50-0.60$ & 95 & \pm 0.04 & \pm 0.02 \\
\hline
\end{tabular}

* Analytical frequency e.g. 95\% means that the chemical composition of $95 \%$ of the melts are within the final range. 


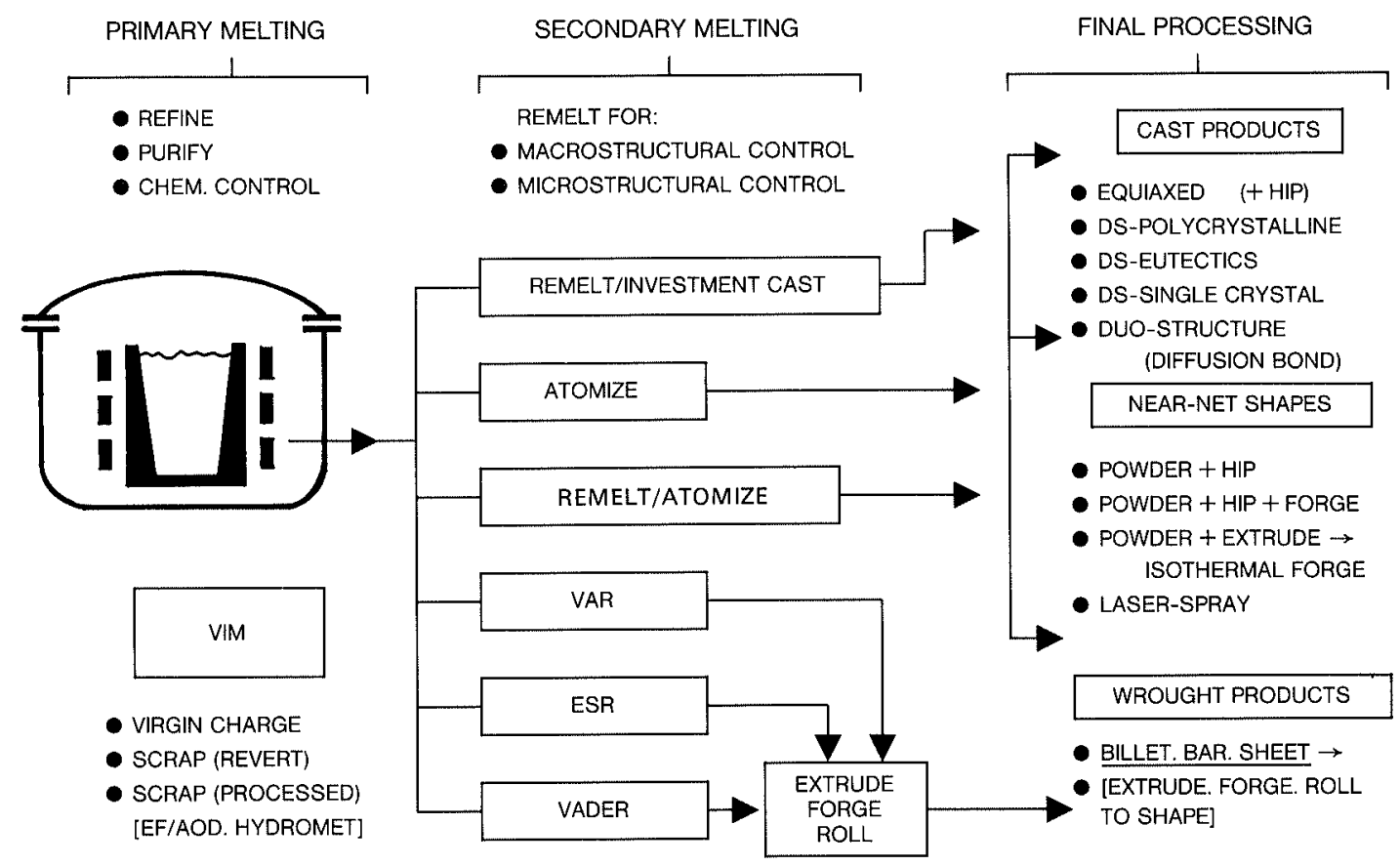

Fig. 1. Processing routes for products cast from VIM-ingots or electrodes.

- isolation of the melt from air contamination: gas atmosphere can be selected at will, resulting in low loss of reactive elements due to oxidation

- achievement of very closely reproducible compositional tolerances

- control of pressure above the melt: thus control of pressure-dependent chemical reactions

- precise temperature control

- excellent homogenization due to inductive stirring

- removal of undesired trace elements with high vapour pressure

- removal of dissolved gases like hydrogen and nitrogen

- removal of oxide inclusions

- low level of environment pollution from dust output.

Figure 1 shows the various uses and applications of VIM. ${ }^{8)}$ The tap weights range from a few $\mathrm{kg}$ to $15 \mathrm{t}$ depending on whether the furnace is designed for precision casting applications, for casting of forging ingots or for the production of electrodes for further remelting.

Melting in an induction furnace shows some specific differences as compared with electric arc furnace or with ladle metallurgical practice. In spite of a relatively intensive melt circulation the desired slag/metal exchange reactions are limited. Due to the characteristic movement of the bath the slag is transported towards the crucible wall, where it solidifies and becomes inactive.

The metallurgical processes such as desulphurization and dephosphorization have, therefore, only a limited effect. An additional disadvantage lies in the fact that the rammed crucible lining undergoes a higher erosion due to slag attack. For this reason, the main metallurgical refining is primarily limited to the purely pressure dependent reactions, such as $\mathrm{C}-, \mathrm{O}-, \mathrm{N}$ - and $\mathrm{H}$-removal, and the evaporation of trace elements with high vapour pressure as in the case of $\mathrm{As}, \mathrm{Cu}, \mathrm{Pb}, \mathrm{Bi}, \mathrm{Te}, \mathrm{Sb}$ and $\mathrm{Sn}$.

\subsection{Slag/Metal-Reactions}

The refractory lining of the crucible of a vacuum
Table 3. Typical refractories for VIM-crucibles for melting of superalloys.

\begin{tabular}{cccc}
\hline $\begin{array}{c}\text { Refractory } \\
\text { type }\end{array}$ & $\begin{array}{c}\text { Max. melt } \\
\text { temperature } \\
\left({ }^{\circ} \mathrm{C}\right)\end{array}$ & $\begin{array}{c}\text { Density } \\
\left(\mathrm{g} / \mathrm{cm}^{3}\right)\end{array}$ & $\begin{array}{c}\text { Thermal shock } \\
\text { resistance }\end{array}$ \\
\hline $\mathrm{MgO}$ & 1800 & 2.8 & Good \\
$\mathrm{Al}_{2} \mathrm{O}_{3}$ & 1900 & 3.7 & Good \\
$\mathrm{MgO}_{3}$-spinell & 1900 & 3.8 & $\begin{array}{c}\text { Poor } \\
\mathrm{Al}_{2} \mathrm{O}_{3} \text {-spinell } \\
\mathrm{ZrO}_{2}\end{array}$ \\
\hline
\end{tabular}

Table 4. Reduction pressures of various crucible materials with Fe-melts $(0.1 \% \mathrm{C})$ at $1600^{\circ} \mathrm{C}$.

\begin{tabular}{cr}
\hline Crucible material & $\mathrm{P}_{\text {co }}$ in Pascal \\
\hline $\mathrm{CaO}$ & 40.0 \\
$\mathrm{ZrO}_{2}$ & 133.3 \\
$\mathrm{MgO}$ & 533.2 \\
$\mathrm{Al}_{2} \mathrm{O}_{3}$ & 533.2 \\
$\mathrm{SiO}_{2}$ & 81313.0 \\
\hline
\end{tabular}

induction furnace has a number of important aspects relevant to refractory/metal- and refractory/slag-interactions. Some of the significant parameters influencing the performance of the crucible are:

- reaction of metal or slag with the crucible lining

- erosion of the lining material

- chemical- and physical stability of the refractories.

Table 3 shows the VIM crucible refractories commonly used today. When selecting the lining refractory the behavior of the oxides under vacuum at elevated temperature must also be considered. The main prerequisite here is that these oxides remain stable when in contact with the melt under the given operating conditions, such as melt composition, pressure and temperature. As the dissociation and reduction of the 
oxides result in the formation of $\mathrm{CO}$, the reduction pressure of these oxides is an important indicator for their suitability. In Table 4 the reduction pressure of various crucible materials at $1600^{\circ} \mathrm{C}$ is listed. It is apparent that $\mathrm{CaO}$ is the most stable crucible lining material. But $\mathrm{CaO}$ is very sensitive to humidity and therefore not suitable for crucible lining in. industrial furnaces. It is further evident from the table, that $\mathrm{ZrO}_{2}$, $\mathrm{MgO}$ and $\mathrm{Al}_{2} \mathrm{O}_{3}$ are quite suitable for refractory lining in a vacuum induction furnace, with $\mathrm{ZrO}_{2}$ the most stable of the three. ${ }^{8)}$ Apart from carbon, superalloys generally contain relatively high concentrations of $\mathrm{Al}$ and $\mathrm{Ti}$. The reduction of the lining material by $\mathrm{Al}$ and/or $\mathrm{Ti}$ must thus also be considered. A recent theoretical investigation of reaction kinetics regarded that an alumina crucible will be most suitable for melting superalloys. ${ }^{9)}$

Slag/metal reactions for desulphurization cause practical difficulties in vacuum induction furnaces. Desulphurization of the melt with a reactive basic slag in a vacuum induction furnace is only carried out in specific cases because of heavy slag attack of the crucible lining. A crucible with rammed lining exhibits low resistance to the refinery slag, which may also contains fluxes such as $\mathrm{CaF}_{2}$. Schlatter ${ }^{7)}$ and Darmara ${ }^{10)}$ achieved good desulphurization results in vacuum induction furnaces with steels and high temperature alloys by using a lime bearing basic slag. Desulphurization primarily occurs via the stable compounds $\mathrm{MgS}$ and $\mathrm{CaS}$. Desulphurizing agents, like $\mathrm{Ca}, \mathrm{Mg}$ and $\mathrm{Ce}$ common in the secondary metallurgy of steel, have also been used for desulphurization of superalloys. With the addition of $0.07 \% \mathrm{Ce}$ in well-deoxidized melts of Inconel 901, sulphur-contents of less than $8 \mathrm{ppm}$ can be achieved. In this case the sulphur is removed by the formation of stable sulphur in $\mathrm{CeS}_{2} / \mathrm{CaS}^{11,12)}$

\subsection{Evaporation Reactions}

For the production of critical aircraft engine components the concentration of certain trace elements such as $\mathrm{Ag}, \mathrm{Pb}, \mathrm{Bi}$ and $\mathrm{Se}$ must be kept very low in superalloys. ${ }^{13)}$ Figure 2 shows the deleterious influence of these elements on stress rupture properties of certain superalloys. ${ }^{14,15)}$ Most of these harmful trace elements, fortunately, have relatively high vapor pressures and can therefore removed by evaporation during melting in vacuum induction furnaces. Figure 3 shows, how various trace elements behave under vacuum. In $\mathrm{NiCr}$-melt elements such as $\mathrm{As}, \mathrm{Sn}$ and $\mathrm{Sb}$ cannot be removed via the gas phase at a pressure of 7 mbar, whereas the elements $\mathrm{Cu}, \mathrm{Pb}$, Se and $\mathrm{Bi}$ are reduced under vacuum to concentrations well below $50 \mathrm{ppm}$ in a relatively short time. ${ }^{16)}$
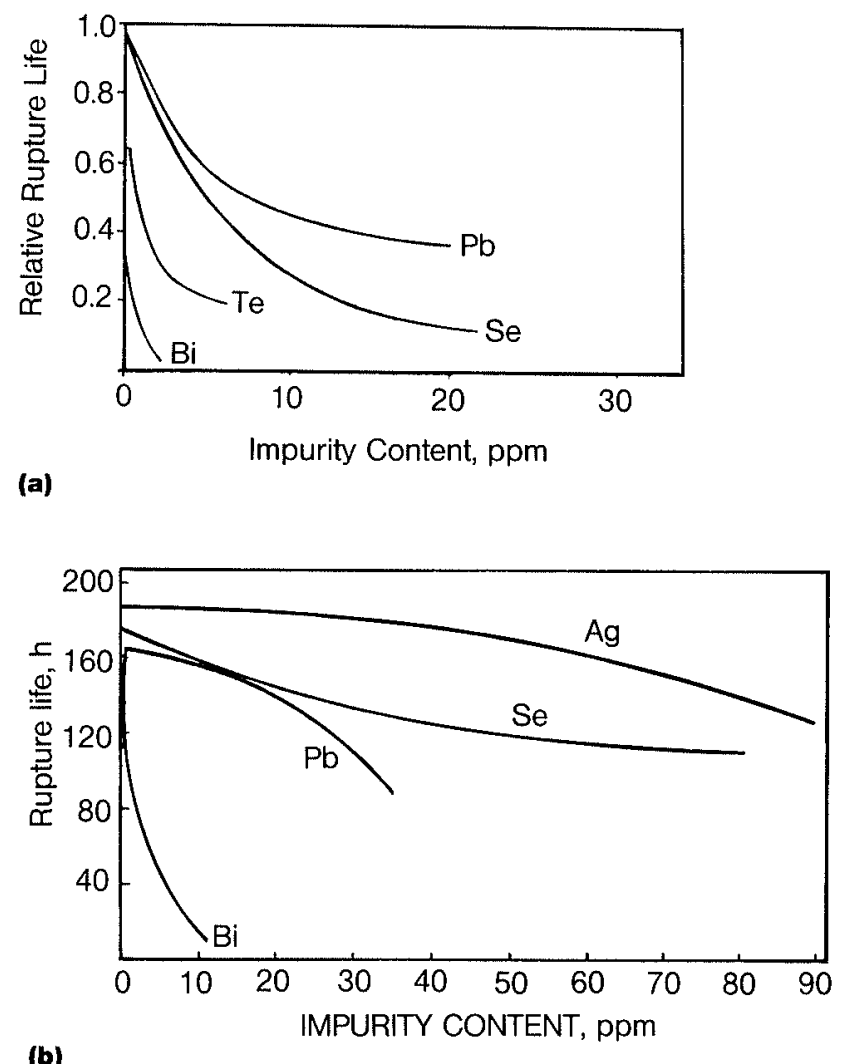

Fig. 2. Effect of various trace elements on the $649^{\circ} \mathrm{C} / 690 \mathrm{MPa}$ stress rupture of Inconel 718.
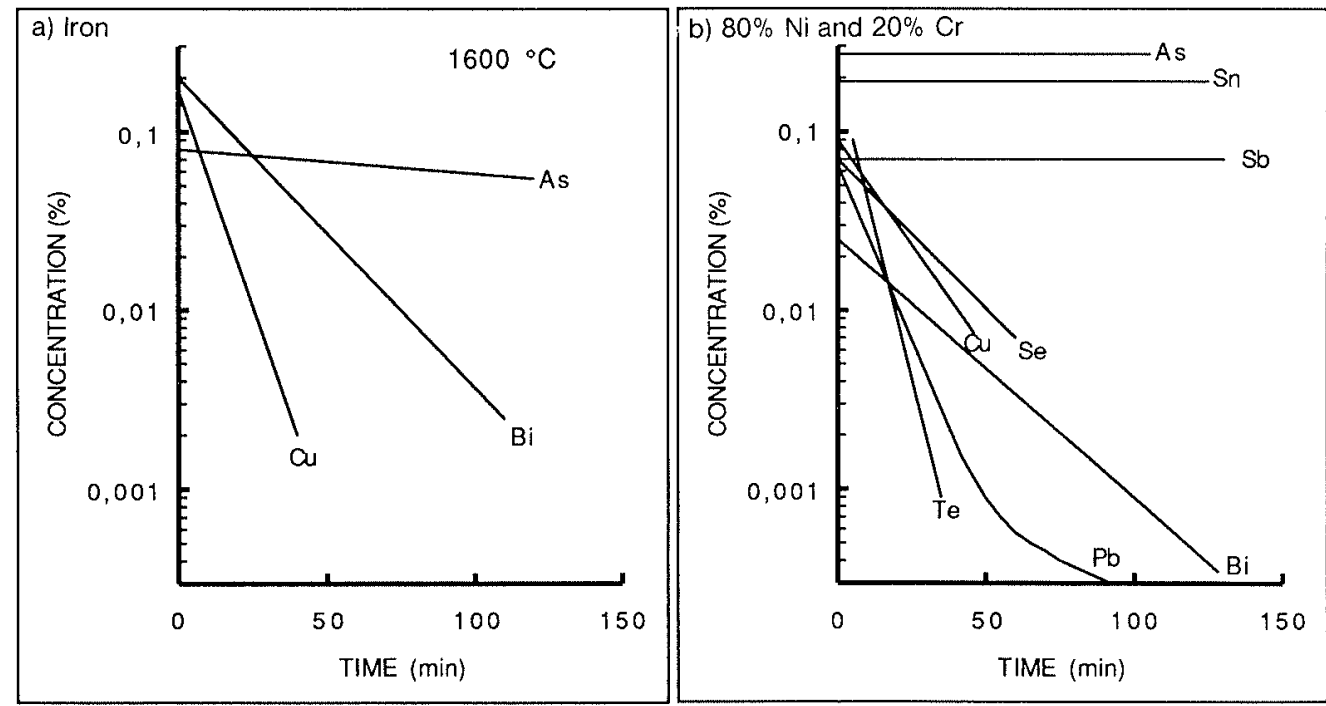

Fig. 3. Evaporation of trace elements in a VIM-furnace at 7 mbar. 


\subsection{Gas Reactions}

The solubility of hydrogen and nitrogen in Ni-basesuperalloy melts depends on chemical composition, temperature and pressure and is governed by Sievert's law:

$$
\begin{aligned}
{[\% \mathrm{H}] } & =K \sqrt{P_{\mathrm{H}_{2}}} \\
{[\% \mathrm{~N}] } & =K \sqrt{P_{\mathrm{N}_{2}}}
\end{aligned}
$$

Hydrogen is easily removed during vacuum induction melting as this element strictly follows Sievert's law. The rate of hydrogen removal is considerably higher during CO-boiling and stirring of the melt. Hydrogenconcentrations of less than $1 \mathrm{ppm}$ are already attained by the time the charge is completely molten.

Nitrogen solubility in Ni-base-melts principally obeys Sievert's law, but the presence of various alloying elements, such as $\mathrm{Cr}, \mathrm{V}, \mathrm{Ti}, \mathrm{Al}, \mathrm{Zr}$, etc., which appreciably reduce the activity of nitrogen influences significantly its solubility. Because of the formation of brittle nitrides or carbon nitrides in superalloys containing strong nitride-forming elements like $\mathrm{Ti}$, the nitrogen content must be kept to the lowest possible level. The removal of nitrogen by vacuum melting was therefore the subject of several investigations. ${ }^{17-19)}$ Simkovich ${ }^{19)}$ investigated the influence of composition, pressure and temperature on nitrogen-removal of $\mathrm{Fe}$ - and $\mathrm{Ni}$-base-alloys. The results showed that under similar vacuum treatment conditions alloys containing up to $15 \% \mathrm{Cr}$ contained comparable residual nitrogen content as the $\mathrm{Cr}$ free alloys. This is due to the fact that $\mathrm{Cr}$ is not a strong nitride-former and accordingly the rate of nitrogen removal from a $\mathrm{Cr}$ containing melt under vacuum is comparable to that from $\mathrm{Cr}$ free melts. The concentration of nitrogen in alloys containing $\mathrm{Cr}$ along with strong nitride-forming elements $\mathrm{Al}, \mathrm{Nb}$ and $\mathrm{Ti}$ was much higher. Another important factor for the removal of nitrogen under vacuum is the concentration of dissolved oxygen and sulphur in the melt. Since oxygen and sulphur are surface active elements in $\mathrm{Fe}$ - and $\mathrm{Ni}$-melts, they tend

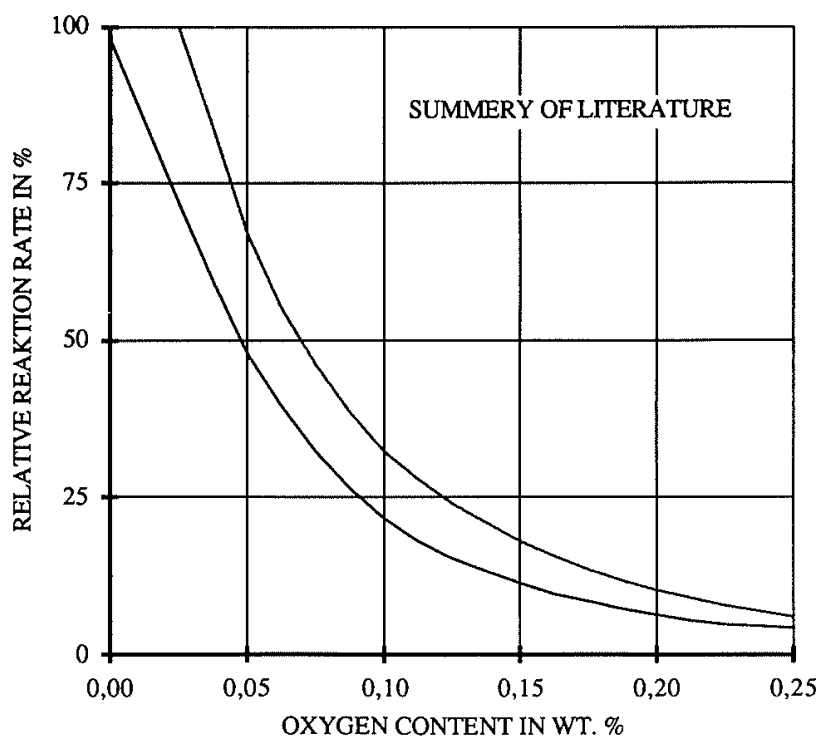

Fig. 4. Effect of oxygen on the reaction rate of nitrogen removal from liquid iron under vacuum. to concentrate near the gas/metal-interface and this limits the transportation rate of nitrogen from the melt into the gas phase. Figure $\mathbf{4}$ shows the effect of dissolved oxygen on the rate of nitrogen-removal of Fe-melts. ${ }^{7)}$ For effective nitrogen-removal and to achieve very low nitrogen content in superalloys like Inconel 718, the following practice is advantageous:

- selection of charging material with very low initial nitrogen- and sulphur-content

- effective and prolonged boiling of the melt (COformation) also during the period of melt down in order to reduce the dissolved oxygen content by C-O-reaction; subsequently, full deoxidation of melt with $\mathrm{Al}$ along with Ar-purging at low pressure

\subsection{Deoxidation via Gas Phase}

The melt can be deoxidized in the vacuum induction furnace through the gas phase according to the following reaction:

$$
[\mathrm{C}]+[\mathrm{O}]=\{\mathrm{CO}\}_{\text {gas }}
$$

As the reaction product is a gas, the oxygen-content at a given carbon-content is directly proportional to CO-partial-pressure at the top of the melt:

$$
\%[\mathrm{C}] \times \%[\mathrm{O}]=K \times P_{\mathrm{CO}}
$$

This deoxidation process, the so-called Vacuum-CarbonDeoxidation (VCD)-Process, for Fe- and Ni-melts is of distinctive advantage for two reasons:

(1) the deoxidation product is a gas and escapes from melt without contaminating the melt with inclusions, and

(2) the reaction is highly pressure dependent and can therefore be controlled by selecting proper pressure during vacuum induction melting.

The theoretical equilibrium value of $[\mathrm{C}] \times[\mathrm{O}]$ product for $\mathrm{Ni}$-melts is in the range of $10^{-7}$ to $10^{-8}$ at $1.33 \mathrm{~Pa} .^{20,21)}$ For usual carbon content of $0.05 \%$ in various superalloys, the theoretical oxygen content at equilibrium is in the range of $2 \mathrm{ppm}$. In industrial melts of Inconel 718 the oxygen content after VCD-treatment at a pressure of $1.33 \mathrm{~Pa}$ is in the range of 10 to $15 \mathrm{ppm}$. Thus, in actual industrial melts the $\mathrm{C}-\mathrm{O}$-reaction does not reach equilibriums owing to the inhibition of CO-nucleation. Additionally, a continuous flow of oxygen into the melt takes place due to the dissociation of the refractory lining of the crucible and leakages of the vacuum chamber at low pressure. Deoxidation of the melt by the $\mathrm{C}-\mathrm{O}-$ reaction proceeds in two steps ${ }^{7,8)}$ :

- boiling phase, i.e. formation of $\mathrm{CO}$-gas within the melt primarily by heterogeneous nucleation with intensive bath turbulence as a result of the formation of this gas

- desorption phase, in which no CO-bubbles form within the melt, with CO-formation taking place only at the melt/vacuum-interface.

The greatest reduction of carbon and oxygen takes place during the first stage, the boiling phase. During the desorption phase there is only a reduction of carbon, but not of oxygen, primarily owing to the dissociation of the crucible lining. The melt must therefore be deoxidized, finally by a strong deoxidizing 
agent like $\mathrm{Al}$ and the reaction product $\mathrm{Al}_{2} \mathrm{O}_{3}$ must be removed during refining of the melt.

\section{Improvements in Oxide Cleanliness}

Oxide cleanliness plays a decisive role in superalloys with their extremely high-strength properties at higher service temperature. Figure $\mathbf{5}$ shows the deleterious

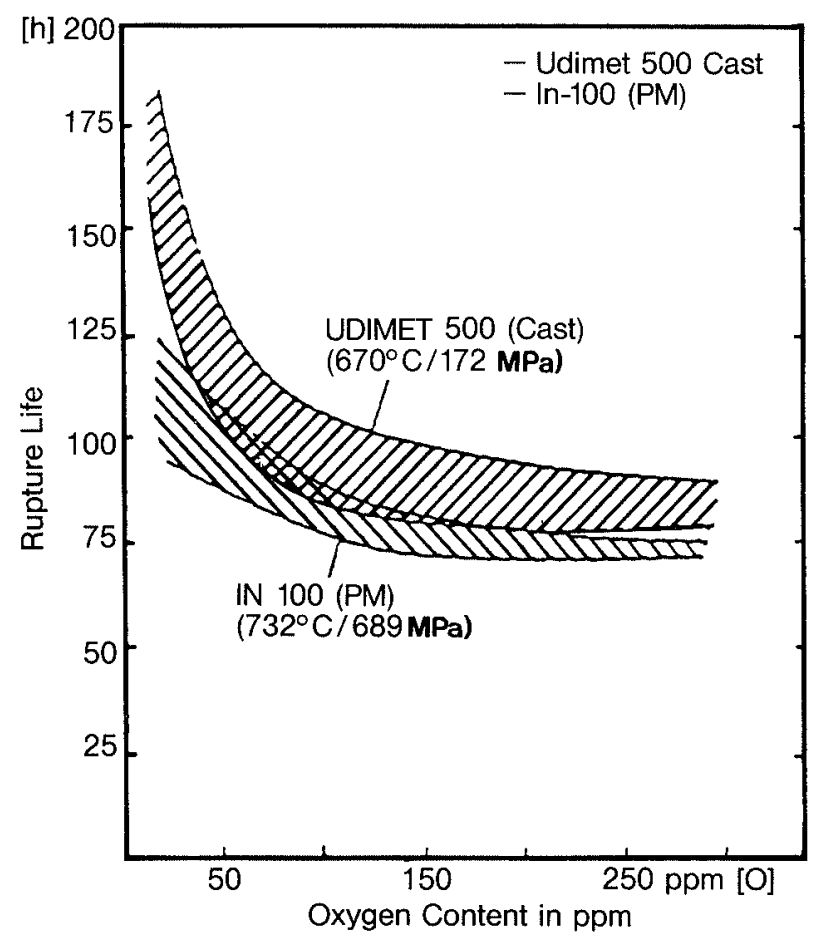

Fig. 5. Influence of oxygen on rupture life. influence of the oxygen content and thus of the oxide cleanliness on the rupture life of superalloys. ${ }^{15)}$ An appreciable removal of the oxide-inclusions is achieved if there is a liquid reactive slag in contact with the melt, which is capable of absorbing oxide inclusions. Active slags are normally not employed in a vacuum induction furnace. This means that the oxides can only precipitate at the crucible wall, which naturally, limits the degree of removal of these inclusions. ${ }^{22}$

As mentioned, the oxygen-pick up from the dissociation and erosion of the crucible lining is an important factor in the final cleanliness of the melt. Consequently, it is of paramount importance to select the right ceramic lining. Apart from that, long dwelling time of the melt in the vacuum induction furnace should be avoided. ${ }^{23)}$

\section{Process Technology, Furnace Conception and Auto- mation}

The refractory crucible can be rammed or brick lined with suitable ceramic material, preferably with $\mathrm{Al}_{2} \mathrm{O}_{3}$ / $\mathrm{MgO}$-spinell. After ramming and before sintering the crucible should be dried at approx. $200^{\circ} \mathrm{C}$ with an electric heater. The furnace is then charged with material, preferably low carbon unalloyed steel scrap, and heated-up by induction to approx. $800^{\circ} \mathrm{C}$ under air atmosphere. After holding the charge at $800^{\circ} \mathrm{C}$ for about $2 \mathrm{hr}$, the furnace is closed and evacuated. The charge is subsequently heated under vacuum to approx. $1700^{\circ} \mathrm{C}$ and held for several hours for final sintering. The melting cycle for superalloys in a VIM-furnace consists of several steps of charging, melting down, refining, chem-

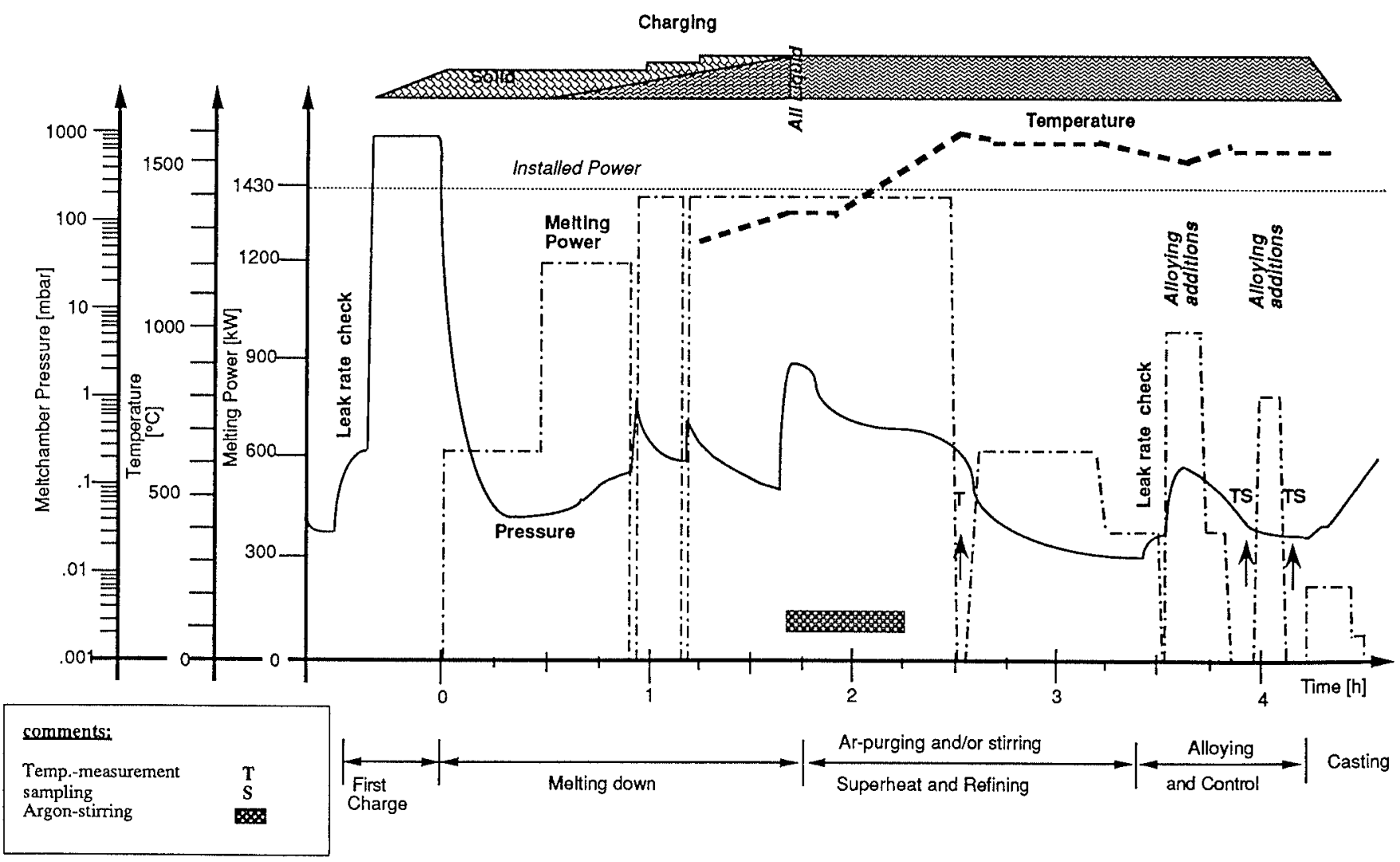

Fig. 6. Typical melting cycle for Inconel 718 in the VIM-furnace. 


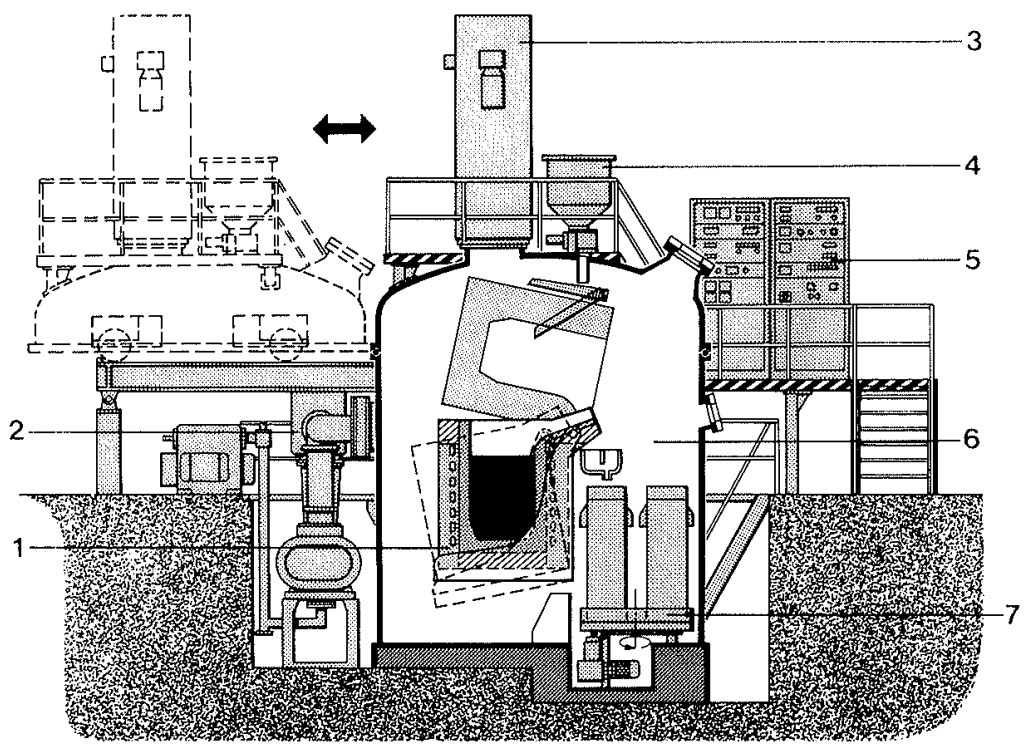

Fig. 7.

Schematic diagramme of a VIM-furnace.

istry correction and casting. A typical melting cycle for Inconel 718 is shown schematically in the pressure-temperature-time-diagramme of Fig. 6. The basic charging material is comprised of alloying elements, except the reactive constituents. Further charging should be carried out under vacuum through a bulk charger located at the top of the furnace. During the melting down- and refining-period relatively high outgassing of the charging material and a strong boiling due to $\mathrm{C}-\mathrm{O}$-reaction takes place. It is necessary to adjust carefully the furnace pressure in order to maintain a well-controlled boil, which is very important for the removal of dissolved gases, including oxygen. The boiling intensity decreases continuously as the oxygen content of the melt is reduced. After completion of this refining period the melt is finally deoxidized and other reactive elements, $\mathrm{Al}$, $\mathrm{Ti}, \mathrm{Zr}, \mathrm{B}$, are added where necessary. After thorough mixing and final chemistry check the proper pouring temperature is adjusted and the melt is poured.

A typical vacuum induction furnace is shown schematically in Fig. 7. As described earlier, the oxygen content of superalloy melts at the end of the refining and deoxidation period is usually in the range of 10 to $15 \mathrm{ppm}$ but it has been found that in the casting such as of electrodes for further remelting, the oxygen content is higher. This is due to the fact that during casting via a tundish ceramic contamination of the melt from the eroded tundish material, caused by heavy turbulence takes place. As the cleanliness of a VAR-ingot depends on the cleanliness of the electrode, it is of vital importance to use a clean electrode to get a cleaner ingot.

A new development in this field of vacuum induction melting is the Vacuum Induction Degassing and Pouring (VIDP)-furnace. The VIDP-furnace-design has an independent melting and treatment unit, which allows use of different casting technique modules (Fig. 8). In comparison with a classical chamber type VIM-furnace (Fig. 7), the VIDP-furnace does not have any vacuum chamber. The furnace body itself is vacuum-tight. Accordingly, the melt chamber volume and the chamber-surface of a VIDP-furnace are much smaller than those of a classical VIM-furnace. Similar to

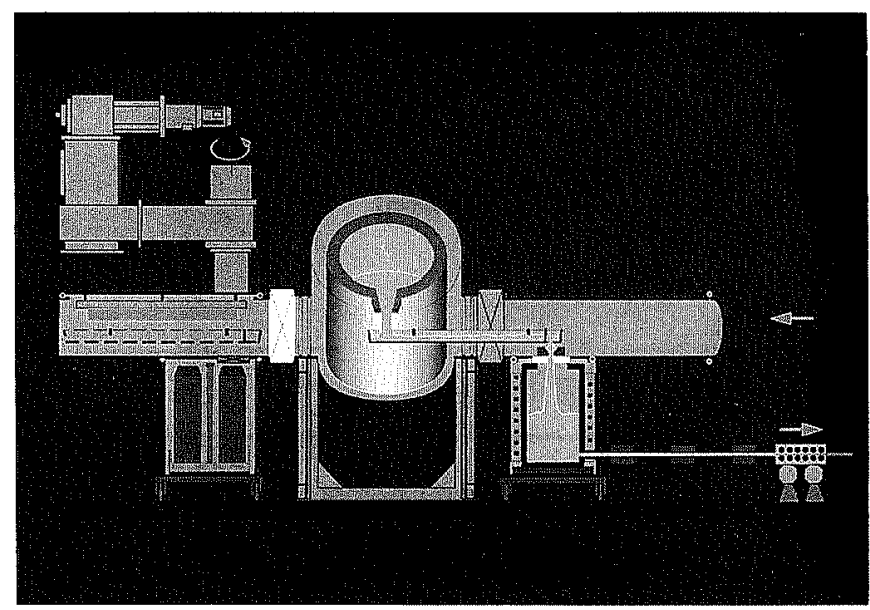

Fig. 8. VIDP-concept with combined ingot/electrode-casting and horizonal continuous casting.

VIM-furnaces, the casting of the melt can be carried out under vacuum or under inert gas atmosphere. All hydraulic systems for tilting and the flexible watercooled power cables are outside the vacuum chamber, which makes the equipment safer. During pouring the furnace body with the coil and the crucible is tilted around a vacuum-tight pouring tunnel. The melt is poured into a preheated launder, which transfers the liquid metal into the casting chamber. The casting chamber can be designed to incorporate ingot molds, ladles, continuous casting or atomizing equipment. Whereas the VIDPfurnace itself is comparable to the classical VIM-furnace in respect to melt treatment under vacuum, the special feature of the equipment is the transport of the melt via a relatively long launder. From the metallurgical point of view, the launder is an important part of the VIDP-furnace for the cleaning of the melt from non-metallic oxide-inclusions. The launder is equipped with two slag barriers. A ceramic filter just before the outlet can also be inserted, if desired (Fig. 9). The launder is conceived in such a way, that a quasi laminar flow of the melt is assured. Accordingly, the removal of oxide-inclusions by flotation during casting is optimized. Recent results have shown that all oxides with diameters 


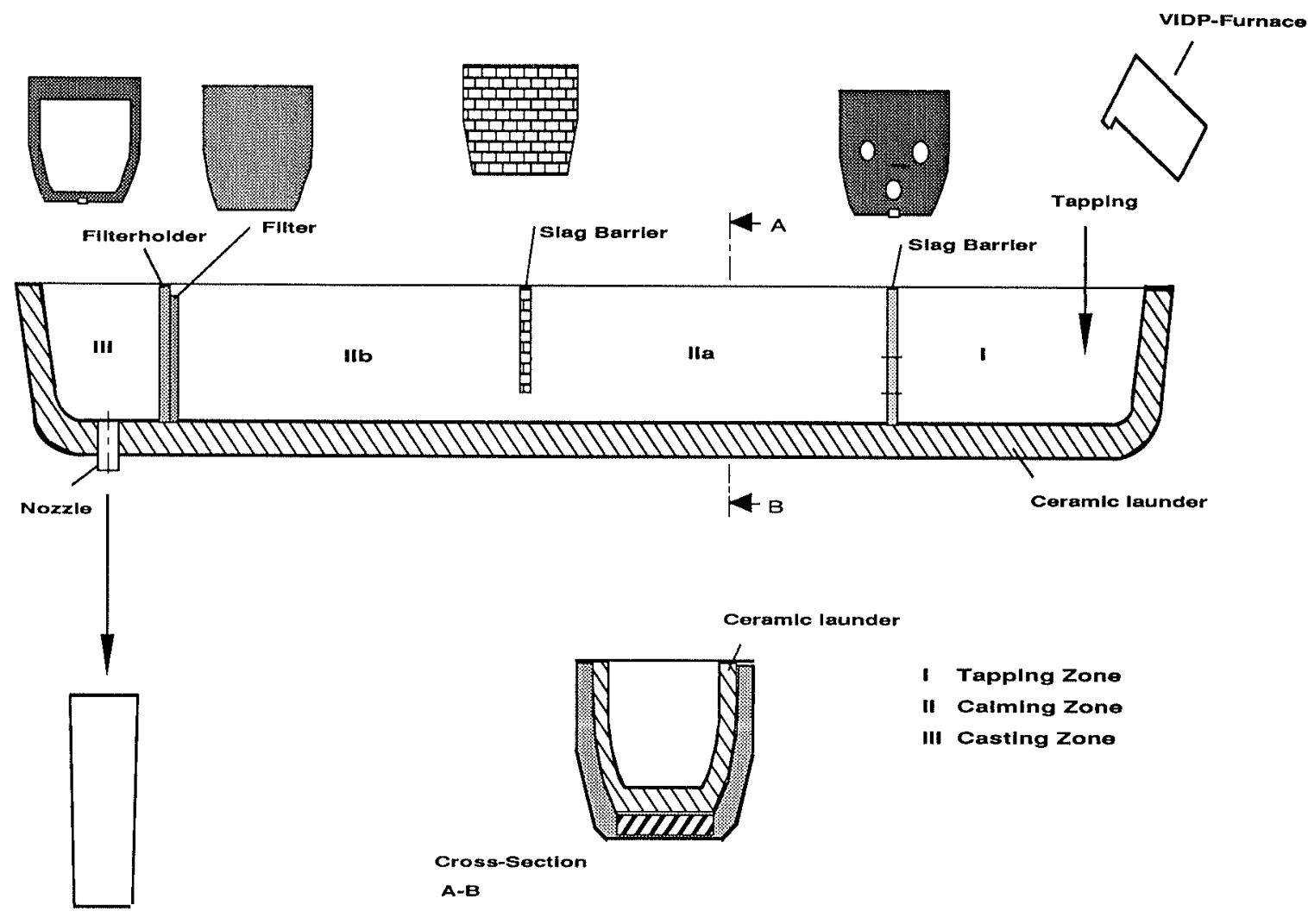

Fig. 9. Schematic of a VIDP-launder.

of more than $15 \mu \mathrm{m}$ have been removed during casting via a launder. ${ }^{24)}$

The use of a programmable logical control system in combination with process computers for the automation of the vacuum induction melting improves melt reproducibility. With such a system, increasingly stringent metallurgical requirements of the future can also be met. Closer analysis tolerances can be achieved by the acquisition, storage and appropriate processing of all the data necessary for the metallurgical process.

The basic concept involves combining the individual modules, such as the opened and closed loop controls of the furnace, computational modules and the alloying- and charge-calculation operation, in order to automate the vacuum induction process to varying degrees up to $100 \%$, depending on requirements. Such systems have been in use for some years now as a successful means for monitoring and controlling the vacuum system or for recording melt parameters, for detection purposes and for the diagnosis of faults.

Using charge- and alloying calculations, it is quite an easy matter nowadays to achieve the required chemical analysis at minimal cost. In the ideal configuration, the process computer is directly linked to the computer of the analysis system so that immediately after the analysis has been made, the additions can be calculated and possibly even automatically weighed and charged to the melt. If the alloy calculation system also features a charge calculation facility, the charge materials and quantities (scrap) can also be optimized at the start of the process. The complete calculation system facilitates accurate computation of the alloying elements starting from the initial quantities and ending with the adjustment values for fine correction at the end of the fining period.

\section{Remelting Process}

Growing demands for superalloy cleanliness and structural homogeneity in particular, cannot be met by vacuum induction melting and casting alone. This has led to the practice of remelting of already melted and refined material (known as electrode) in a watercooled copper crucible. Principally three processes, vacuum arc remelting, electroslag remelting and electron beam remelting, combined with a controlled solidification in a watercooled crystallizer have been developed and in commercial use. The newest development in this respect is the application of a plasma torch for remelting purposes. Figure 10 shows the various process combinations for the production of superalloys.

\subsection{Vacuum Arc Remelting (VAR)}

The vacuum arc remelting process was the first commercial remelting process for superalloys. It was used in the late 1950 s to manufacture materials for the aircraft industry. The primary feature of vacuum arc melting and remelting is the continuous melting of a consumable electrode (manufactured in a vacuum induction furnace) by means of a dc arc under vacuum. The molten material solidifies in a watercooled copper mold.

The basic design of a VAR-furnace has remained largely unchanged over the years; however, significant advances have been made in the field of control and regulation of the process with the object of achieving a fully automatic melting procedure. This, in turn, has had a decisive positive influence on the metallurgical properties of the products. The manufacture of homo- 


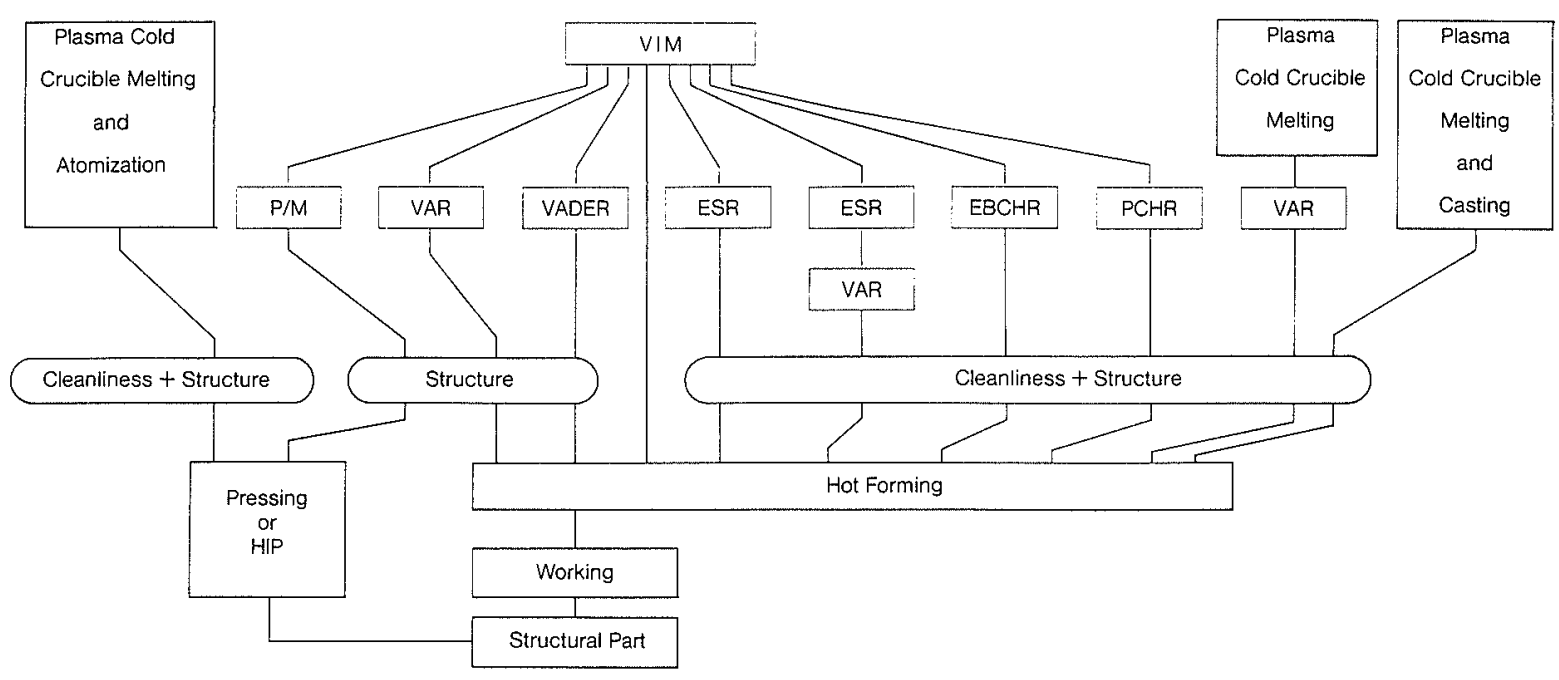

Fig. 10. Various process combinations for superalloys.

geneous ingots with minimal segregation requires careful machining of remelting parameters. Of these, the melting current density and melt rate have the greater influence on the melting bath geometry and conditions of solidification.

The primary benefits of melting a consumable electrode under vacuum are:

- Removal of dissolved gases such as hydrogen and nitrogen

- Minimizing the content of undesirable trace elements with high vapor pressure

- Improvement of oxide cleanliness

- Achievement of directional solidification of the ingot from bottom to top in order to avoid macrosegregation and to minimize microsegregation.

Oxide inclusion removal is optimized because of the relatively short reaction paths during melting of the hot electrode end and because of a good drop dispersion in the plasma arc. Oxide removal is achieved by chemical and physical processes. Less stable oxides or nitrides are thermally dissociated or are reduced by carbon present in the alloy and are removed into the gas phase. However, in superalloys and in high-alloyed steels the non-metallic inclusions, e.g. alumina and titanium carbonitride, are very stable. The removal of these inclusions during remelting takes place only by flotation. The remaining inclusions in the solidified ingot are small and evenly distributed in the cross section. The solidification structure of an ingot of a given composition is a function of the local solidification time and the temperature gradient at the liquid/solid interface. To achieve a directed dentritic primary structure, a relatively high temperature gradient at the solidification front must be maintained during the entire remelting period. Accordingly, the growth direction of the cellular dentrites corresponds to the direction of the temperature gradient or the direction of the heat flow at the moment of solidification at the solidification front. The direction of the heat flow is always perpendicular to the solidification front or, in the case of curved interface, perpendicular to the tangent. The growth direction of the dentrites is a function of the metal pool profile during solidification.

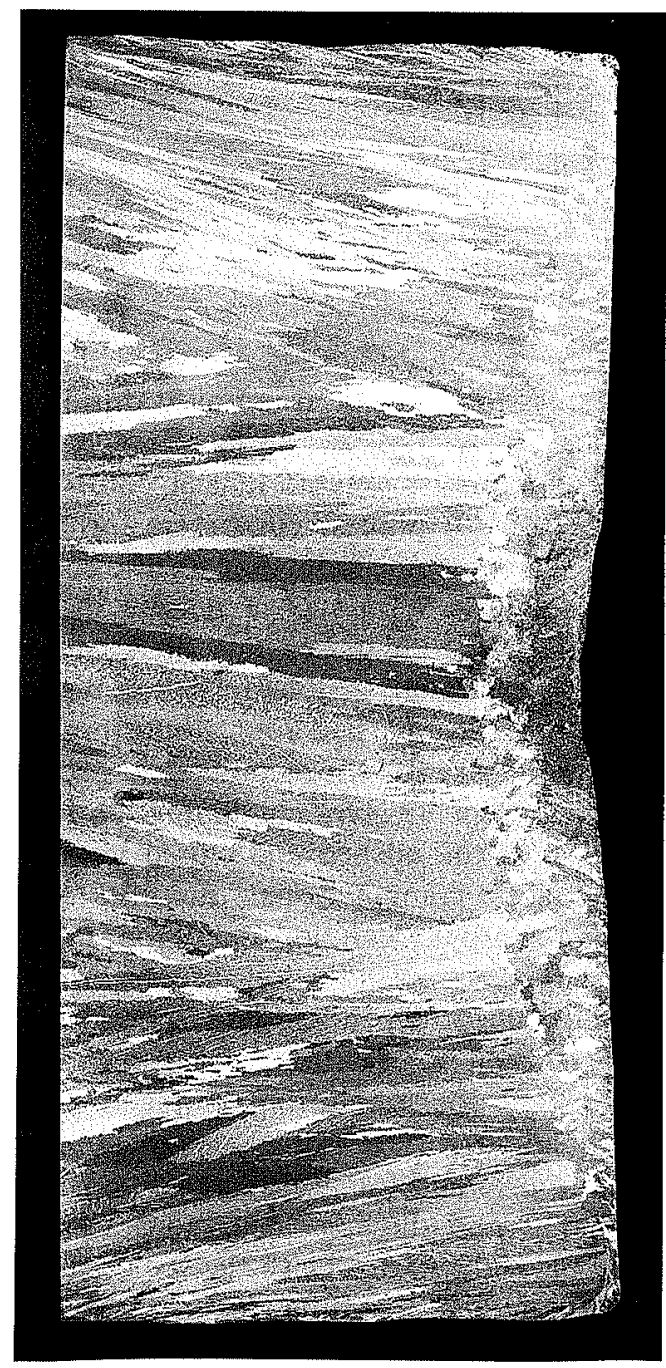

Fig. 11. Top longitudinal section of cast $-50 \% \mathrm{HCl} / 50 \%$ ferric-chloride grain etch.

The pool depth increases with melting rate. Thus the gradient of the dentrites, with respect to the ingot axis, increases with melting rate. In extreme cases, the growth of the directed dentrites can come to a stop. The ingot core then solidifies nondirectionally in equiaxed grains, which leads to segregation and microshrinkage. Even 
in the case of directional dentritic solidification, the microsegregation increases with dentrite arm spacing. A solidification structure with dentrites almost parallel to the ingot axis (as shown in Fig. 11) yields optimal results. However, this is not always possible. A good ingot surface requires a minimum energy input and, accordingly, a minimum melting rate. Optimal melt rates and energy inputs depend on ingot diameter. This means, that the necessary melting rate for large-diameter ingots cannot be maintained for crystallization parallel to the ingot axis.

The ingot diameter for several superalloys like Inconel 718 or Waspaloy is therefore limited and is less than $500 \mathrm{~mm}$. Figure 12 shows melting rates for various steels and alloys as a function of ingot diameter. These are empirical values that were obtained from experience in operation. These melting rates gave low microsegregation while achieving acceptable surface quality.

In spite of directional dentritic solidification, such defects as tree ring patterns, freckles and white spots can occur in a remelted ingot. This can lead to rejection of the ingot, particularly in the case of superalloys. Tree ring patterns can be identified in a macroetched transverse section as light-etching rings. They usually represent a negative crystal segregation. Tree ring patterns seem to have little effect on material properties. They are the result of a wide fluctuation in the remelting rate. In modern remelting plants, however, the remelting rate is maintained at the desired value by precise control during operation, so that it exhibits no significant

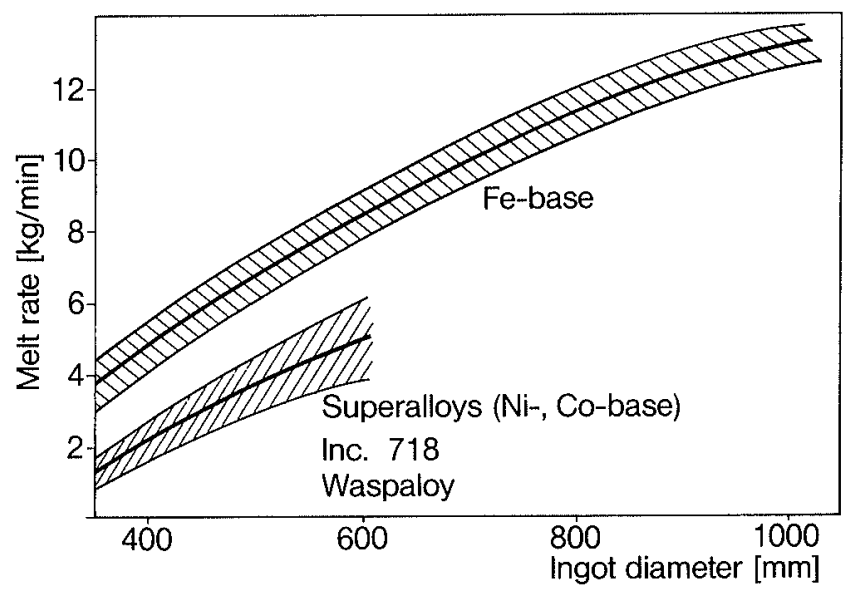

Fig. 12. Typical melt rates for different grades. fluctuation.

Freckles and white spots have a much greater effect on material properties than tree ring patterns, especially in superalloys. Both defects represent an important cause of the premature failure of turbine discs in aircraft engines. Freckles are dark-etching circular or nearly circular spots that are generally rich in carbides or carbide-forming elements. The formation of freckles is usually a result of a high pool depth and most frequently in a rotating liquid pool. The liquid pool can be set in rotation by stray magnetic fields during remelting. Freckles can be avoided by maintaining a low pool depth and by avoiding the disturbance of magnetic fields through the use of a coaxial current supply.

White spots are typical defects in VAR-ingots. They are recognisable as light-etched spots on a macrometched surface. They are low in alloying elements, e.g. titanium and niobium in Inconel 718. There are several mechanisms that could account for the formation of white spots 25 ):

- Unmelted dentrite clusters dropping from the cast electrode

- Particles which falls from the crown which forms around the edge of the mold

- Particles disintegrating from the solidified edge (shelf) of the ingot top.

All three of the above mentioned mechanisms, individually or combined, can be considered as sources of white spots. This indicates that white spots cannot completely be avoided during vacuum arc remelting. To minimize the frequency of occurence of these defects, the following conditions should be observed during remelting:

- Use the maximum acceptable metal rate permitted by the ingot macrostructure

- Use a short arc gap to minimize crown formation and to maximize arc stability

- Use a homogeneous electrode free of cavities and cracks.

As mentioned earlier, the melt rate is an important factor in the quality of the ingot macrostructure. A modern VAR-plant is therefore equipped with a load cell system to measure the weight of the electrode of a particular interval of time. The actual values of the melt rate are compared by computer with the desired set

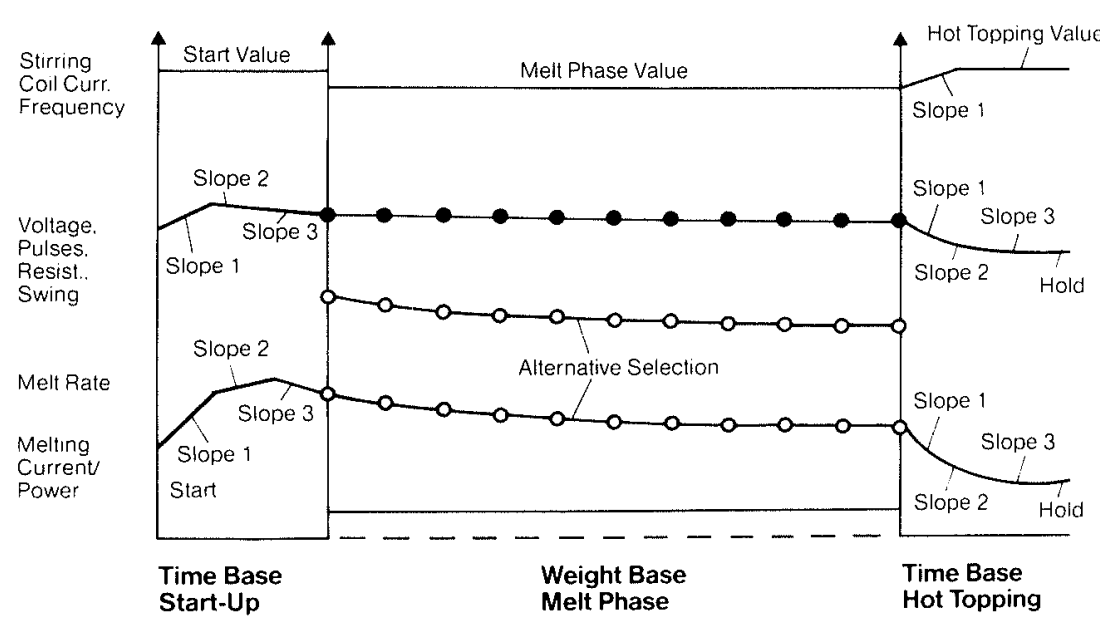

Fig. 13.

Control parameters and setpoint functions. 
values. Any difference between the measured melt rate and the desired value is eliminated by the proper accommodation of the power input. Figure 13 shows the melt rate and the melting current at start-up, during steady-state melting and during hottopping. Start-up and hottopping are usually controlled based on time. The melting phase is controlled based on weight. The hottopping begins when a preselected residual weight is reached. A computer controls the melting parameters, which are stored in the form of recipes in the computer.

\subsection{Electroslag Remelting (ESR)}

The theory behind this process was known in the 1930s, but a general breackthrough for this process took more than 30 years. Intensive studies carried out in the Soviet Union, Germany, United Kingdom, Austria and Japan after World War II made the use of the electroslag remelting possible on a production scale. ${ }^{26-28)}$ In contrast to the vacuum arc remelting (VAR), the remelting in the ESR-process does not occur by striking an arc under vacuum. The ingot is builtup in electroslag remelting in a watercooled mold by melting a consumable electrode immersed in a superheated slag usually under normal atmosphere. The heat required is generated by an electrical current (usually ac) flowing through the liquid slag, which provides the electrical resistance. As the slag.temperature rises above the liquidus temperature of the metal, the tip of the electrode melts.

The molten metal droplets fall through the liquid slag and are collected in the watercooled mold. During the formation of the liquid film, the metal is refined and cleaned of contaminants, such as oxide-and sulphideparticles. The high degree of superheat of the slag and, partially, of the metal favors the slag/metal-reaction. Melting in the form of metal droplets greatly increases the metal/slag-interface surface area. The intensive reactions between metal and slag result in a significant reduction in sulphur and non-metallic inclusions. The reduction of non-metallic inclusions is better than with the VAR-process. The remaining inclusions are very small and are evenly distributed in the remelted ingot. Another feature of the ESR-process, as in vacuum arc remelting, is the directional solidification of the ingot from bottom to top.

The special feature of the ESR-process is that a continuous transport of liquid metal through the slag takes place. During this transport, the slag and the metal compositions chang according to the kinetic and thermodynamic conditions. To perform its intended function, the slag must have some well-defined properties, for example:

- Its melting point must be lower than that of the metal.

- It must be electrically efficient.

- Its composition should be such that the desired reactions like removal of sulphur and oxides are ensured.

- It must have suitable viscosity at remelting temperature.

Slags for the electroslag remelting are usually composed of calcium fluoride $\left(\mathrm{CaF}_{2}\right)$, lime $(\mathrm{CaO})$ and alumina $\left(\mathrm{Al}_{2} \mathrm{O}_{3}\right)$. Magnesia $(\mathrm{MgO})$, Titania $\left(\mathrm{TiO}_{2}\right)$ and silica $\left(\mathrm{SiO}_{2}\right)$ are also added, depending on the alloy to be remelted.

One of the primary advantages of the ESR-process is the good desulphurization of the metal. The final desulphurization is determined by two reactions. The first is the metal/slag-reaction, in which sulphur is transferred from the metal to the slag:

$$
[\mathrm{S}]+(\mathrm{CaO})=(\mathrm{CaS})+[\mathrm{O}]
$$

The second reaction is the slag/gas phase-reaction. In this case, the sulphur absorbed by the slag is removed by the oxygen of the gas phase in the form of gaseous sulphur oxide:

$$
(\mathrm{CaS})+3 / 2 \mathrm{O}_{2 \text { gas }}=(\mathrm{CaO})+\mathrm{SO}_{2 \text { gas }}
$$

It is evident that a saturation of the slag with sulphur does not take place, therefore, the desulphurization capacity of the slag remains intact throughout the entire remelting process. With a highly basic slag $\left(\mathrm{CaO} / \mathrm{SiO}_{2}\right.$ greater than 3), more than $80 \%$ of the sulphur can be removed.

As mentioned previously, the ESR-process is usually carried out under a normal air atmosphere. Oxidation of the metal is unavoidable. Oxygen can be transferred into the metal in several ways:

- Oxidation of the electrode surface above the slag bath - Oxidation of the slag surface of elements with variable valences such as iron and manganese

- Rust attached to the electrode surface

- Transfer of oxygen due to desulphurization according to $\mathrm{Eq}$. (5).

This results in losses of easily oxidizable elements such as titanium, aluminium and silicon. During remelting of Fe-based alloys this oxidation is usually compensated by a continuous deoxidation of the slag, preferably with aluminium. In case of superalloys such as Inconel 718 or Waspalloy with relatively high titanium and aluminium content the deoxidation of $\mathrm{CaF}_{2}-\mathrm{CaO}$ $\mathrm{Al}_{2} \mathrm{O}_{3}$-slag does not help much to assure the desired narrow analytical range of these elements in the remelted ingot. The introduction of oxygen into the superalloy melt is primarily caused by the ESR-slag constituents $\mathrm{FeO}, \mathrm{SiO}_{2}$ and $\mathrm{Al}_{2} \mathrm{O}_{3}$.

Due to the very low $\mathrm{FeO}$ - and $\mathrm{SiO}_{2}$-content of the slag the reaction between titanium and these oxides is of minor importance, so that the actual oxidation of titanium takes place according to the equation:

$$
3[\mathrm{Ti}]+2\left(\mathrm{Al}_{2} \mathrm{O}_{3}\right)=3\left(\mathrm{TiO}_{2}\right)+4[\mathrm{Al}]
$$

By applying the law of mass action, the equilibrium condition can be expressed in a simplified manner by the equation:

Table 5. Al- and Ti-contents after electroslag remelting of Inconel 718 .

\begin{tabular}{lccc}
\hline & Electrode & \multicolumn{2}{c}{ ESR-ingot } \\
& & Top & Bottom \\
\hline Ti in \% & 1.05 & 1.04 & 1.04 \\
Al in \% & 0.57 & 0.52 & 0.55 \\
\hline
\end{tabular}




$$
\frac{[\mathrm{Ti}]^{3}}{[\mathrm{Al}]^{4}}=K \frac{\left(\mathrm{TiO}_{2}\right)^{3}}{\left(\mathrm{Al}_{2} \mathrm{O}_{3}\right)^{2}}
$$

In order to avoid a $\mathrm{Ti}$-loss in the melt, the $\mathrm{TiO}_{2}$-content should be adjusted for given $\mathrm{Al}_{2} \mathrm{O}_{3}$-content of the slag to achieve equilibrium for a given [Ti]/[Al]-ratio of the superalloy (balanced slag system). Table 5 shows the content of $\mathrm{Ti}$ and $\mathrm{Al}$ in an ESR-ingot remelted with a balanced slag but without any deoxidation of the slag during remelting. All superalloys with $[\mathrm{Ti}] /[\mathrm{Al}]-$ ratio of 3 or less can be remelted with a balanced slag without any problems. For higher $[\mathrm{Ti}] /[\mathrm{Al}]$-ratio in the alloy, such as A286, a deoxidation, even of the balanced slag, will be necessary during remelting under air atmosphere. ${ }^{29)}$

The solidification of an ESR-ingot is governed by the same thermodynamical laws as in the case of VARprocess. The melting rate here is also the essential factor influencing the pool depth and, accordingly, the ingot structure. In order to achieve a primary structure free from any macrosegregation, a directed solidification must be assured. The melt rate depending on ingot diameter is of similar order of magnitude as in the VAR-process. Here also the ingot diameter of some segregation-sensitive super-alloys is limited to max. $500 \mathrm{~mm}$. As in a VAR-ingot, structural defects, e.g. tree rings, patterns and freckles, can occur in an ESR-ingot. The reason for occurrence of these defects and means for their avoidance are the same as described in the VAR-process. It is, of course, important to note that white spots normally do not occur in an ESR-ingot, as there are no crowns above the solidifying ingot and no shelf formation. The relics of unmelted dentrites from the consumable electrode can, of course, fall down, but they have to pass through the superheated slag and are melted. Significant advances have been made in the last few years in plant design, especially in the area of process control and coaxial power supply. Figure $\mathbf{1 4}$ shows schematically a modern ESR-furnace. Figure 15 shows two modern ESR-furnaces each with two melting stations for remelting of superalloys. The ESR-process has been extensively automated in a manner similar to that accomplished in the case of VAR-furnaces. The remelting process takes place under fully automatic control. Table 6 shows a comparison between the features offered by the ESR-process and those by the VAR-process. ${ }^{22)}$

\section{Summary}

The increasing demand for very narrow analytical range of the chemical composition, very low concentration of harmful trace elements and gases along with

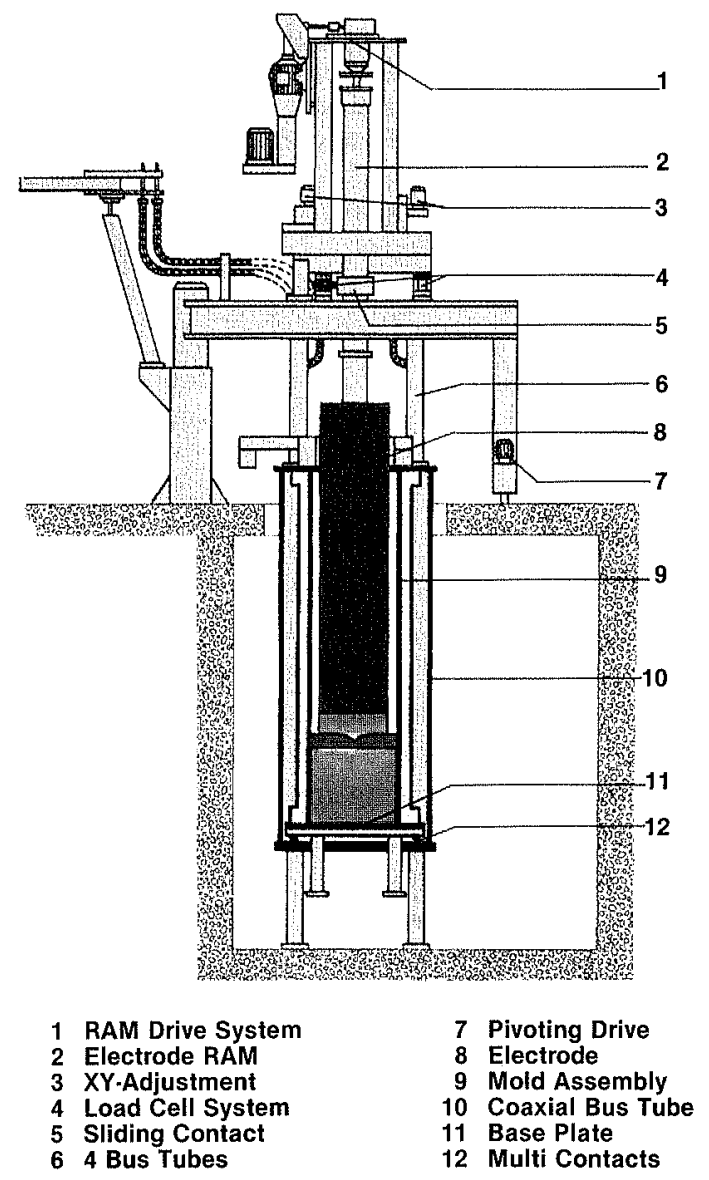

Fig. 14. Schematic of an ESR-furnace with a stationary mold.

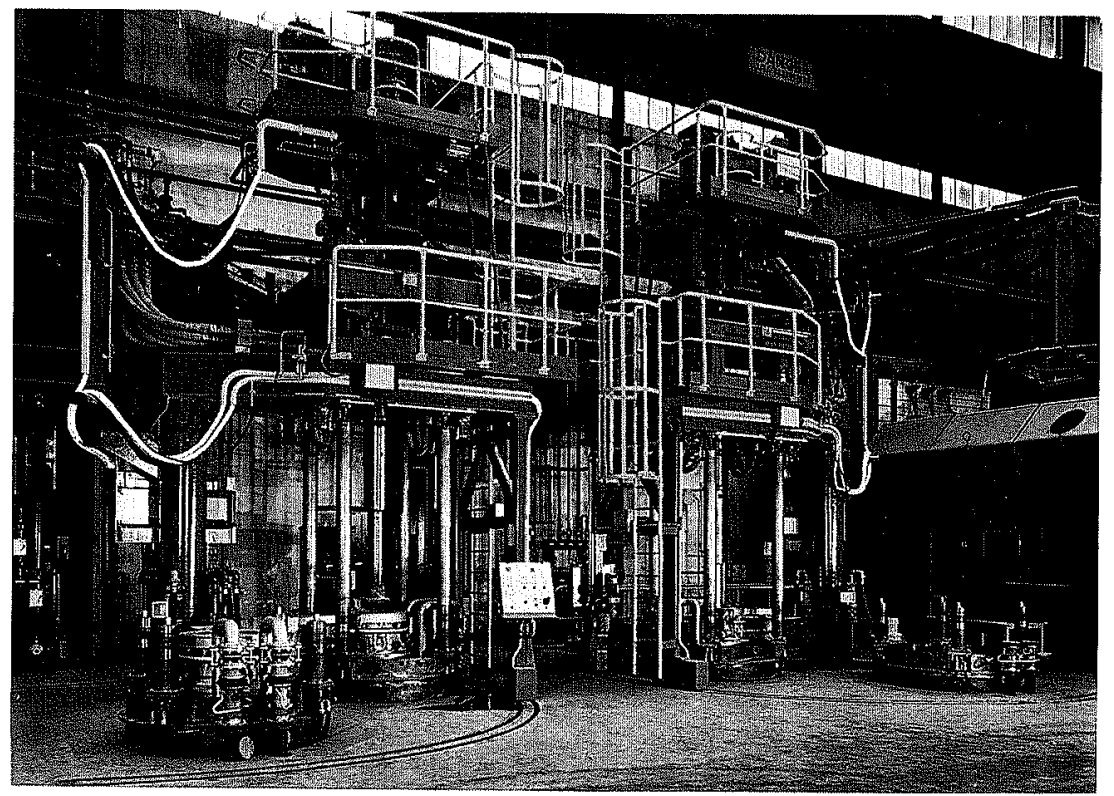

Fig. 15.

Modern ESR-furnace. (Courtesy of Wiggin Alloys, Hereford/UK) 
Table 6. Special features of the Automatic Melt Control (AMC)-system.

\begin{tabular}{lcc}
\hline \multicolumn{1}{c}{ Features } & VAR & ESR \\
\hline Complete automatic operation of the furnace by preset melt profiles & $\times$ & $\times$ \\
Automatic start-up and hottopping by preset current-time profile & $\times$ & $\times$ \\
Automatic start-up and hottopping by preset power-time profile & $\times$ \\
Melt rate control maintaining a preset melt rate profile & $\times$ \\
Alternatively selectable current control maintaining a preset profile & \\
Alternatively selectable power control maintaining a present profile & $\times$ \\
Preset profiles for arc gap control (voltage, pulse rate); arc gap is controlled by slave processor board fully & $\times$ \\
integrated in AMC & \\
Preset profiles for immersion depth control (resistance, swing) & $\times$ \\
Computer-calculated basic speed of feed based on melt geometry and melt rate & $\times$ \\
Preset profiles for stirring coil (current, reversal time) & $\times$ \\
Preset profile for operating pressure (optional) & $\times$ \\
Monitoring of selectable limits for melt rate and melting power & $\times$ \\
Free selection of four melt parameter signals onto four analog outputs & $\times$ \\
Color-plotter software package for four free selectable melt parameter signals & $\times$ \\
Function keys to influence programme execution such as hold, run, step-forward, break-off, start & $\times$ \\
hottopping & $\times$ \\
Printed melt record containing process data as well as special events; events are printed with elapsed & $\times$ \\
actual time & $\times$ \\
Video terminal designed for simple dialog for data entry; graphic display available & $\times$ \\
Established melt profiles are stored on hard disk and on floppy disk for backup purposes & \\
Integrated diagnostic maintainance programme & $\times$ \\
Host computer interface with own CPU & $\times$ \\
\hline
\end{tabular}

an exceptional cleanliness in sophisticated superalloys makes the vacuum induction melting of these alloys absolutely necessary. Vacuum induction melting is a versatile process and allows independent control of temperature and pressure. A stirring of the melt, either inductive or by Ar-bubbling influences the mass transport to a great extent, which accelerates the desired metallurgical reaction favourably. A relative new development of the classical VIM-furnace is the VIDPfurnace with a long launder. Pouring the melt via launder by creating a quasi-laminar flow greatly improves the degree of oxide removal.

In spite of the large metallurgical potential of VIMfurnaces the solidification of the ingots or electrodes cannot be controlled, which results in unacceptable inhomogeneity of the primary structure. Hence a second step of remelting with controlled directed solidification in a watercooled copper mold is inevitable. The secondary remelting of VIM-cast electrodes is carried out either in a vacuum arc furnace or an ESR-furnace. With proper controll of the process, especially of the melt rate, macrosegregation-free ingots can usually be produced by both means.

\section{REFERENCES}

1) M. J. Donachie, Jr: Superalloys Source Book, American Soc. Met., Metals Park, Ohio, (1984), 3.

2) C. Le Chevallier et al.: Rev. Met., (1980), 791.

3) H. Burghardt and G. Neuhof: Steelmaking, VEB-Verlag für Grundstoffindustrie, Leipzig, (1982), 391.

4) W. Esmarch: Wissenschaftliche Veröffentlichung Siemens, 10 (1931), 173
5) W. Zschintzsch: Die neue Giesserei, 39 (1952), 381.

6) F. Neumann and F. Hegerwaldt: Stahl Eisen, 94 (1974), 53.

7) T. Schlatter: J. Met., 24 (1972), 17.

8) J. W. Pridgeon et al.: Metall. Treat., (1981), 261.

9) K. Yeum and D. R. Poirier: Proc. 9th Int. Conf. Vacuum Metallurgy, San Diego, Ca., (1988), 68.

10) F. N. Darmara: J. Met., 19 (1967), 42.

11) R. E. Bailey et al.: Proc. 3rd Int. Symp. of Superalloys, Seven Springs, Pa., (1976), 109.

12) M. F. Rothman: Trans. Vacuum Metall. Conf., (1977), 49.

13) R. T. Holt and W. Wallace: Int. Met. Rev. Review 203, The Met. Soc., (1976), 1.

14) W. B. Kent: J. Vacuum Sci. Tech., 11 (1974), 1038.

15) P. Hupfer: Fachberichte Hüttenpraxis Metallverarbeitung, (1986), 773.

16) P. P. Turillon: Trans. 6th ICVM, (1963), 88.

17) G. K. Sigworth Trans. Met. Soc. Canadian Inst. Met.,(1977), 104.

18) W. A. Fischer: Arch. Eisenhüttenwes., 33 (1960), 1.

19) A. Simkovich: J. Met., 253 (1966), 504.

20) K. W. Krone: Ph. D. Thesis of the Technical University of Aachen, Germany, (1969).

21) M. Gard et al:: Proc. Con. Int. Sur Les Applications Des Technique Strasbourg, (1967), 177.

22) A. Choudhury: Vacuum Metallurgy, ASM-Int., Metals Park, Ohio, (1990), 37

23) W. H. Sutton and E. Manner: Proc. 6th ICVM, San Diego, Ca., (1979), 340.

24) A. Choudhury et al:: Paper presented at ATS-Steelmaking Day, Paris, (1990).

25) A Mitchell: Proc. Vac. Met. Con. on Special Metals Melting, Pittsburgh, (1986), 55.

26) W. Holzgruber and E. Plöckinger: Stahl Eisen, (1968), 638.

27) A. Choudhury et al.: Stahl Eisen, (1968), 1193.

28) A. Choudhury et al:: Arch. Eisenhüttenwes., (1971), 299.

29) A. Choudhury et al: Proc. Vac. Met. Con. on Special Metals Melting, Pittsburgh, (1986), 141. 